\title{
A Research Review of flexible Pavement Temperature Profile
}

\author{
Fajing Pan ${ }^{1,}$, Lei Wang ${ }^{2, b}$ Jinke $\mathrm{Ji}^{2, \mathrm{c}}$ Wang Jing ${ }^{3, \mathrm{~d}^{*}}$ \\ ${ }^{1}$ Henan Zhongyuan Highway Corporation Ltd, Zhengzhou, China, 450052 \\ ${ }^{2}$ Henan Zhuxin Highway Extension Engineering Ltd, Xinyang, China , 464000 \\ ${ }^{3}$ Beijing University of Architecture and Civil Engineering, BJTICR Centre, Beijing, China 100044 \\ axu-sf@126.com,,18601227805@163.com, ${ }^{c} 15210612705 @ 163 . c o m$, \\ d*wangjing2705@163.com,
}

Keywords: Flexible pavement; Temperature Profile; Prediction approach; Performance influence Abstract. This paper presents the current researches about temperature profiles in multilayered flexible. The measurement methods of temperature profiles to the prediction model for temperature distribution in pavement structures are summarized and discussed. The temperature influence on bearing capability and performance of flexible pavement are analyzed. The approaches of considering temperature factor in different asphalt pavement design methods are summarized. It is suggested that the related researches about temperature profiles in asphalt pavement should be carried out in China and the temperature factors should be considered in the design methods in the future.

\section{Introduction}

The flexible pavement structure is subjected to the compound effect of various environmental and traffic load. The main factor of environmental is the complex distribution of temperature profile in flexible pavement. Due to asphalt binder and asphalt mixture are viscoelastic plastic materials, the strength and modulus of these materials is different under the various temperatures. as results of that, a different types of flexible pavement damage appear. For example, the pavement will be cracking at low temperatures, and be rutting in high temperatures. So the temperature influence on bearing capability and performance of asphalt pavement can not be ignored.

\section{Actual measurement of temperature profile of road and prediction research}

\section{The research on actual measurement of temperature}

The research of temperature profile already begun in very early, Barber in 1957, according to meteorological data study how to calculate the internal temperature profile of asphalt pavement ${ }^{[}$ ${ }^{1]}$.However there are many defects in his prediction model. For example, the date considered only total solar radiation, without considering the amount of solar radiation per hour and so on. Rumney and Jimenez in 1969 according to the Nomogram to estimate the asphalt surface and pavement temperature conditions in the depth of $50 \mathrm{~mm}^{[2]}$. The pavement temperatures and solar radiation were collected per hours. Dempsey in 1970 established a pavement temperature profile prediction model based on the basic theory of heat transfer and ability to balance the asphalt pavement surface ${ }^{[3]}$. Until the United States long-term pavement performance of the project (LTPP) developed, the measurement of Asphalt Pavement Temperature Field began to enter the peak. The research on actual measurement of temperature got very wide attention.

Since 1987, the US Strategic Highway Research Project (SHRP) established a 20-year long-term pavement performance research projects for more depth of understanding pavement performance. The LTPP project was established about 2500 test pavement sections in North America. It covered a variety of different types of pavement structures and different climatic conditions. To further detailed study of climatic conditions affecting the pavement performance, the 61 LTPP test sections was specifically chosen for the season monitor project (SMP) in the test section. 


\section{Research on methods of prediction}

Currently the methods of asphalt pavement temperature profile prediction divided into two categories:

1).Mathematical statistics. The method is obtained a relationship between the asphalt pavement temperature of different depth and solar radiation depths by the method of statistical regression.For example the research of Bosscher et al, Marshall et $\mathrm{al}^{[4]}$ and Park et $\mathrm{al}^{[5]}$

2). Theory method. The method according to the basic theory of heat transfer and energy balance theory to predict the temperature profile which in the asphalt changes.For example the research of Solaimanian and Kennedy ${ }^{[6]}$, Hermansson.

EICM model (Enhanced Integrated Climatic Model) is the most widely used in the entire above model. This model is a analysis program which can analysis the coupling temperature and humidity profile of one-dimensional pavement structure. It can analyze the impact of environmental factors on the pavement structure, such as temperature, rainfall, wind speed and solar radiation on the pavement structure. The initial version of EICM genus ICM model, developed by the Lytton et al in 1993, Then after the upgrade and revision, In 1997 Larson and Dempsey has developed a new model called EICM model based on Integrated Climatic Model $^{[7]}$.EICM model consists of four subblocks. According Birgisson and NewComb findings in MN / Road (Minnesota Road Research Project), EICM model can more accurately estimate seasonal changes situation of temperature profile in asphalt pavement. The EICM model is used as calculation of basic parameters in the method of pavement experience design in the United States.

\section{The main factors affecting the temperature field of asphalt pavement}

Temperature is an important indicator to determine the temperature of the road surface. The historical temperature situation indicates that the temperature pavement over a long period of time. But in order to determine the pavement temperature, which temperature data we choose is still in dispute. The temperature data in the AASHTO design method ${ }^{[8]}$ was obtained according to the results of Southgate and Deen in 1993, It is required to use the temperature data of the previous 5 days. In addition, some asphalt pavement temperature prediction method only needs the temperature data of the previous day.

In addition to the temperature, the solar radiation can also make the road surface temperature increased, but the impact of solar radiation on the asphalt pavement temperature will be even greater. The daily solar radiation changes with the sun's position, in the absence of dark clouds, the solar radiation will reach the maximum in July 21 st, and in December 21 st reached the minimum value. The altitude of the position will also affect the amount of solar radiation. In the summer, the amount of daily solar radiation in the north and the south is the same, but the intensity of the solar radiation in the South will be even greater. The difference in the intensity of solar radiation per hour will increase the gap between the temperature and the road surface temperature. So the maximum radiation intensity and the total amount of solar radiation is equally important to the pavement temperature.

\section{The effect of temperature on asphalt pavement performances}

\section{The effect of temperature on asphalt mixture}

Asphalt mixture is viscoelastic plastic material; it's modulus changes with temperature, many researchers studied on how to determine asphalt mixture modulus change under different temperature conditions. American Asphalt Institute proposed a function that the modulus of asphalt mixture is related with pavement temperature, physical properties of asphalt mixture, and load frequency, as following: 


$$
\begin{aligned}
\lg E= & 5.553833+0.028829 \frac{P_{200}}{f^{0.17033}}-0.03476\left(V_{v}\right)+0.070377\left(\eta_{70^{0} F, 10^{6}}\right) \\
& +0.000005\left(t_{p}^{(1.3+0.49825 \lg f)} P_{a c}^{0.5}\right)-0.00189\left(t_{p}^{(1.3+0.49825 \lg f)} \frac{P_{a c}^{0.5}}{f^{1.1}}\right) * 0.931757\left(\frac{1}{f^{0.02774}}\right)
\end{aligned}
$$

$E$ :Dynamic modulus of asphalt mixture

$P_{200}$ :The passing rate of the aggregate in the No. 200 sieve $f:$ Loading Frequency

$V_{v}$ :Porosity of mixture; $\quad \eta_{70^{\circ} F, 1^{6}}$ :Absolute Viscosity $P_{a c}$ :asphalt content ;

$t_{p}:$ Pavement Temperature, $\square$.

\section{The effect of temperature on structural performance of asphalt pavement}

Change of modulus of asphalt mixture will significantly affects structural bearing capacity and pavement performance of asphalt pavement, Modulus of asphalt mixture is a function of temperature .It changes constantly within one day or even one year .So temperature can affect the structural bearing capacity of asphalt pavement in the following respects:

1)Modulus of asphalt mixture is directly related to temperature. The modulus gradually reduced with the temperature improved, which may cause the reducing of structural bearing capacity.

2)Higher stress is transmitted to base and subbase according to the decrease of asphalt mixture modulus. However, material properties of base are related to stress condition. Base material, especially granular material, will be consolidated under the high stress condition, but cohesive soil will be more vulnerable. Therefore, the temperature condition of asphalt mixture will directly affects material properties of base and subbase.

3)Stress caused by temperature changes: according to microscopic mechanical model, in the case of temperature increase, the contact force among the granules of granular base will be bigger, leading to the increase of volume stress. According to the research results of Van Gurp, with higher degree of compaction and lower initial volume stress level, the influence of temperature on modulus is more significant.

4)The increase of temperature of asphalt pavement structure will reduce the pore water tension in upper layer. It can result in water in base transfers to upper layer which makes pore water pressure reduce. Effective stress of base or soil foundation will be lower. At the same time, the modulus of material is decreased.

The results showed that the effect of temperature on structural bearing capacity of asphalt pavement is quite complicated and it is difficult to separate single factor among complicated factors that exist in each other. Structural bearing capacity of asphalt pavement varies with the change of temperature field. This means that even at the same loads, stress distribution of pavement varies in different time. Therefore, failure mode of asphalt pavement change with time .

\section{The temperature factor of Asphalt Pavement Design}

In TRB ( Transportation Research Board ) meeting in 1992, Monismith presented a process based on the experience in mechanical design method. In the design process, the properties of pavement materials, traffic, climate, and service performance influence each other and jointly determine the demand for the required pavement structure combination ${ }^{[9]}$. In 1994, Deacon et al put forward a set of computing method, which introduce the temperature factor as a major factor in the asphalt pavement design method,he use the concept of Temperature Equivalency Factors ${ }^{[10]}$, this concept convert the design effect times of axle load in different temperature into a standard reference temperature condition .Before this, in the asphalt pavement design method,people usually used the average temperature, the 
number of axle load is practical role in times and there is no equivalent conversion. In addition, there are also a lot of different considerations for temperature factors in different asphalt pavement design method, such as the SHRP method considering the experience of asphalt pavement in low temperature and high temperature, and provides the corresponding forecast formula.1993 version of AASHTO design method recommended calculating the depth, middle and bottom temperature averages to represent the temperature of asphalt pavement. When the pavement temperature appear gradient, Van Gurp recommend to calculate the weighted average temperature as asphalt pavement temperature according to different depth of pavement temperature, The formula of calculating the weighted average temperature can get from Nijboer about trabecular bending of the equivalent concept. According more accurate method to consider the non-uniform distribution of temperature, the thickness of asphalt pavement could be divided into several levels within the scope depth.Analysis shows that the division level method and the method of equivalent temperature of asphalt pavement obtain similar results.

\section{Conclusion}

The measuring methods of temperature profiles and the prediction models for temperature in $p$ avement structures are reviewed. The temperature influence on the physical properties of bituminous materials was discussed. Furthermore, the temperature influence on bearing capability and the performances of flexible pavement were evaluated. The approaches of considering temperature factor in different flexible pavement design are aslo introduced .

\section{References}

[1] Barber, E.S. Calculation of Maximum Pavement Temperature from Weather Reports. Highway Research Board Bulletin, 1957

[2] Rumney, T. N., and Jimenez, R. A. Pavement temperatures in the southwest. Highway Research Record No. 361, National, Research Council, Washington, D.C. 1969

[3] Dempsey, B.J., H. Hill, Characterizing Temperature Effects for Pavement Analysis and Design. Transportation Research Record, 549, 1987

[4] Marshall, C., Meier, R. W., and Welsh, M Seasonal temperature effects on flexible pavements in Tennessee. Transportation Research Record, 1764, 2001.

[5] Park, D., Buch, N., and Chatti, K..Effective layer temperature prediction model and temperature correction via falling weight deflectometer deflections. Transportation Research Record 1764, 2001.

[6] Solaimanian, M., and Kennedy, T. W. Predicting maximum pavement surface temperature using maximum air temperature and hourly solar radiation. Transportation Research Record 1417, 1993

[7] G. Larson and B. J. Dempsey. Enhanced Integrated Climatic Model Version 2.0. Contract DTFA MN/DOT 72114. 1997.

[8] AASHTO. AASHTO Guide for the Design of Pavement Structures.403. Washington, D.C., American Association of State Highway Officials. 1993.

[9] C. L. Monismith, Analytically-Based Asphalt Pavement Design and Rehabilitation-Theory to Practice (1962-1992), TRB Distinguished Lecture. Transportation Research Record 1354, 1992.

[10] S. R. Bigl and R.L.Berg. Modeling Mn/Road Test Sections with the CRREL Mechanistic Pavement Design Procedure. CRREL Special Report 96-21. 1996. US Army Corps of Engineers. Cold Regions Research \& Engineering Laboratory 